Portland State University

PDXScholar

1990

\title{
Audiological in-service regarding hearing impairment and its impact on communication in the geriatric population
}

Marie Barlow Lassell

Portland State University

Follow this and additional works at: https://pdxscholar.library.pdx.edu/open_access_etds

Part of the Geriatrics Commons, and the Speech and Hearing Science Commons Let us know how access to this document benefits you.

\section{Recommended Citation}

Lassell, Marie Barlow, "Audiological in-service regarding hearing impairment and its impact on communication in the geriatric population" (1990). Dissertations and Theses. Paper 4069.

https://doi.org/10.15760/etd.5953

This Thesis is brought to you for free and open access. It has been accepted for inclusion in Dissertations and Theses by an authorized administrator of PDXScholar. Please contact us if we can make this document more accessible: pdxscholar@pdx.edu. 
AN ABSTRACT OF THE THESIS OF Marie Barlow Lassell for the Master of Science in Speech Communication: Speech and Hearing Sciences presented May 3, 1990.

Title: Audiological In-Service Regarding Hearing Impairment and its Impact on Communication in the Geriatric Population.

APPROVED BY THE MEMBERS OF THE THESIS COMMITTEE:
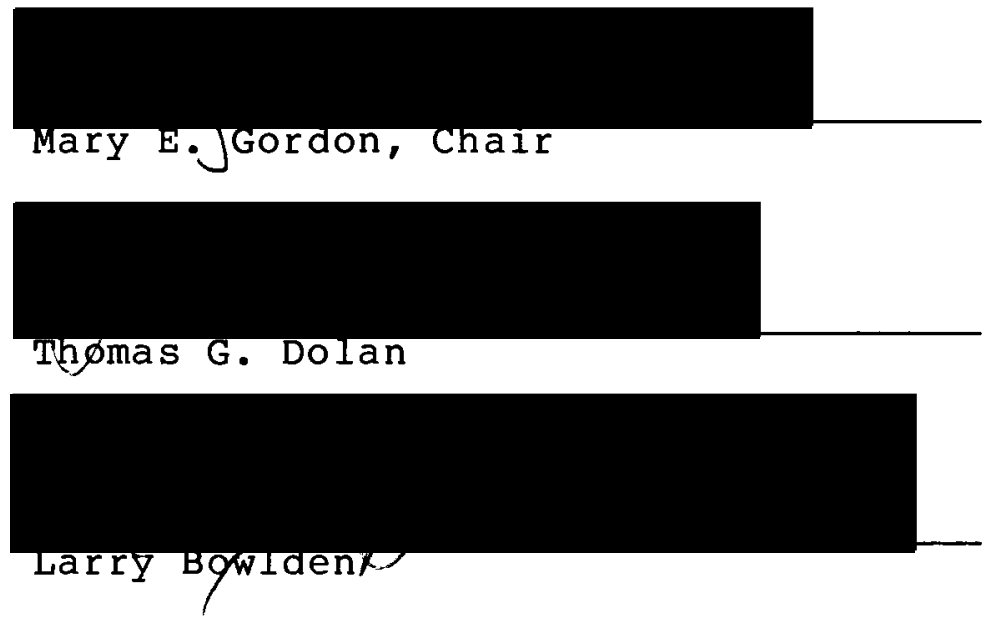

At least two studies have been found conducted in the area of audiological in-services and their impact on the people to whom they were presented. In 1981, Dancer and Keiser studied the effects of empathy training on geriatric-care nurses and in 1985, Dampier, Dancer, and Keiser studied changing attitudes of college students toward older persons with hearing loss. Both of the 
studies investigated the effect of in-service training on empathy, rather than using the traditional academicallyoriented in-service program approach. Both studies found statistical results indicating a significant positive change in the subjects' feelings toward hearing impaired geriatrics. Additionally, Dancer et al. (1981) found a positive significant change in the subjects' perceptions of hearing impaired elderly persons.

This study investigated the effect of an in-service training program on nursing home personnel. The inservice that was developed included both empathy training and factual information. It was hypothesized that both elements are inportant and the inclusion of both could result in a greater change in people's attitude. The empathy portion of this in-service included a taped interview with a hearing impaired older person, a tape dramatizing interactions between hearing impaired and normal hearing individuals, simulated high frequency hearing loss, an "unfair listening test;" and suggestions for interacting with hearing impaired people. The factual information included anatomy and physiology of the ear, types of hearing loss, common characteristics of hearing loss among older people, and the impact of hearing loss on speech understanding. 
This in-service was given to the personnel at three nursing homes. Pre- and post-rating scales were completed using the same assessment scale which Dancer and Keiser (1981) and Dampier et al. (1985) had used. The subjects were asked to complete a 25 item bi-polar, semanticdifferential scale in response to two statements: (a) Hearing impaired elderly people are , and (b) I feel toward hearing impaired elderly people.

The Wilcoxon Matched-Pairs signed Ranks test was used to determine if the rating scores on the pre- and posttests differed. Results showed no significant difference between the pre- and post-ratings for either the subjects' feelings about or perceptions of hearing impaired elderly people.

Various possible factors could have affected the outcome of this study. The pre- and post-rating instrument may have not been sensitive enough to measure subtle changes in attitude. Most sites and employees were reluctant to give one hour out of their workday, which was required to complete the study, possibly creating responses which were less than favorable on the pre- and post-ratings. The largest group of subjects were required to attend the in-service which appeared to create an atmosphere of resentment and non-cooperation. The results of this study led this researcher to 
recommend the development of a more sensitive rating instrument and that attendance be voluntary for such inservices. The format and/or content of the in-service could be re-evaluated. Shorter in-services, over a period of time may be more effective. The factual information could take another direction such as, hearing aids or troubleshooting. Perhaps the entire in-service could be experiential, such as "hands on" work with hearing aids, listening tests, etc. since all three groups responded positively to activities which required participation. 
AUDIOLOGICAL IN-SERVICE REGARDING

HEARING IMPAIRMENT AND ITS IMPACT ON COMMUNICATION

IN THE GERIATRIC POPULATION

by

MARIE BARLOW LASSELL

A thesis submitted in partial fulfillment of the requirements for the degree of

\author{
MASTER OF SCIENCE \\ in \\ SPEECH COMMUNICATION : \\ SPEECH AND HEARING SCIENCES
}

Portland State University

1990 
TO THE OFFICE OF GRADUATE STUDIES:

The members of the Committee approve the thesis of Marie Barlow Lassell presented May 3, 1990.
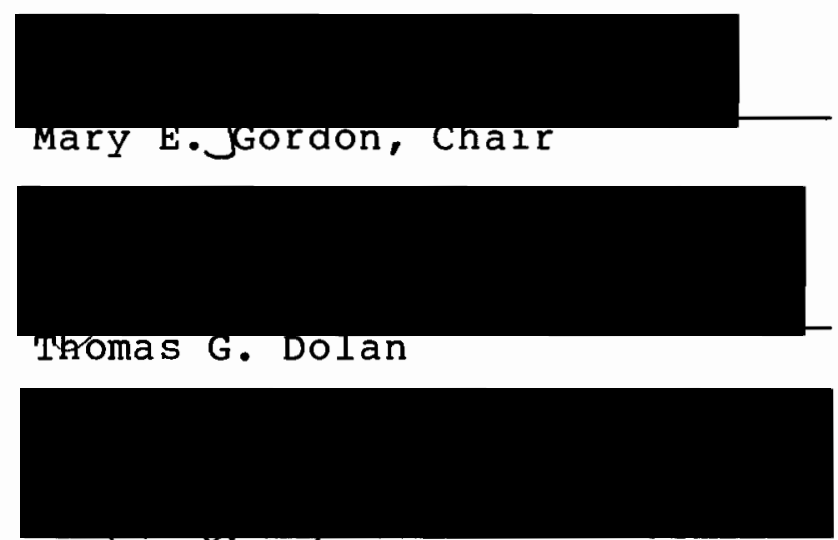

Larry Bowlaen

APPROVED :

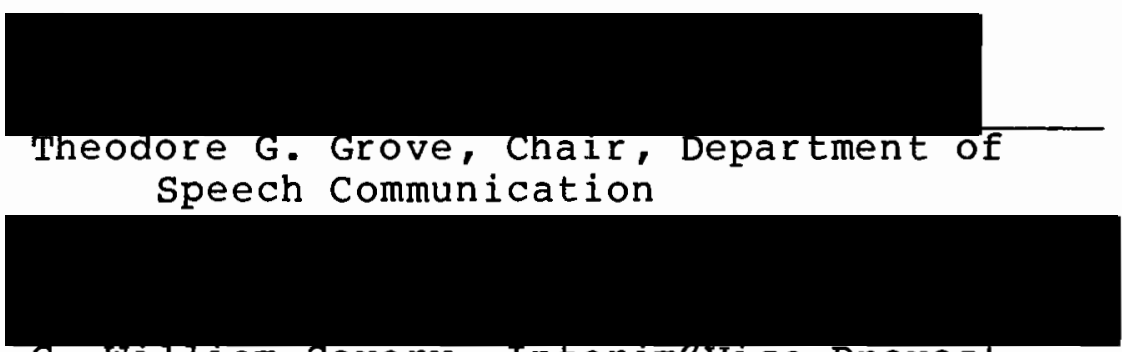

c. WIIIIam savery, Interimuvice provost

for Graduate studies and Research 


\section{DED ICATION}

To my bright and beautiful daughter -- Sarah:

Always listen to your inner wisdom. 


\section{ACKNOWLEDGEMENTS}

Thank you Ruth, Pat and Elizabeth for nurturing and supporting me. Your gift of inclusion kept my spirit moving through the last month of this process.

A special thank you to Mary Gordon and the other members of my committee, Tom Dolan and Larry Bowlden.

Good for you Marie! 
TABLE OF CONTENTS

PAGE

ACKNOWLEDGEMENTS

i i i

LIST OF TABLES

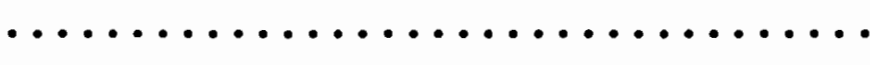

vi

CHAPTER

I INTRODUCTIONS AND STATEMENT OF PURPOSE ...

statement of purpose $\ldots \ldots \ldots \ldots \ldots \ldots$

I I REVIEW OF THE LITERATURE $\ldots \ldots \ldots \ldots \ldots \ldots \ldots$

Hearing Loss in the Aging ..........

In-Service Training ............ 12

II I METHODS $\ldots \ldots \ldots \ldots \ldots \ldots \ldots \ldots \ldots \ldots \ldots \ldots$

General Plan ................. 16

subjects $\ldots \ldots \ldots \ldots \ldots \ldots \ldots \ldots \ldots \ldots \ldots$

Instrumentation $\ldots \ldots \ldots \ldots \ldots \ldots \ldots$

Procedures $\ldots \ldots \ldots \ldots \ldots \ldots \ldots \ldots \ldots \ldots \ldots$

IV $\quad$ RESULTS $\ldots \ldots \ldots \ldots \ldots \ldots \ldots \ldots \ldots \ldots \ldots \ldots \ldots \ldots . \ldots \ldots$

Discussion .................... 23

V SUMMARY AND IMPLICATIONS $\ldots \ldots \ldots \ldots \ldots \ldots .27$

Summary ..................... 27

Implications .................. 29 
APPENDIX

A INFORMED CONSENT ..................... 35

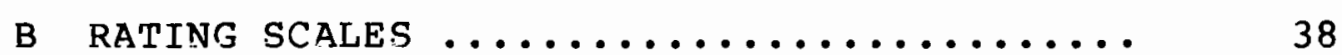

C INSTRUCTIONS FOR COMPLETING THE SCALE .... 41

D OUTLINE OF IN-SERVICE SCRIPT PRESENTED TO NURSING HOME PERSONNEL REGARDING HEARING LOSS AND THE ELDERLY ................

E HANDOUTS FOR IN-SERVICE ..............

F STATISTICAL DATA FROM PRE- AND POST-

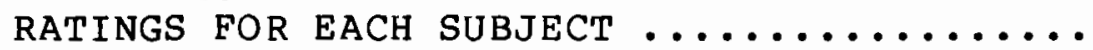




\section{LIST OF TABLES}

TABLE

PAGE

I Wilcoxon Matched Pairs Signed-Ranks Test Results on Changed Attitudes Following an In-Service on

Hearing Impaired Geriatrics . . . . . . . . . . 22 


\section{CHAPTER I}

\section{INTRODUCTION AND STATEMENT OF PURPOSE}

Incidence of significant hearing loss among nursing home residents has been estimated to be from $50 \%$ (Bloomer, 1960) to as high as 908 (Chaffee, 1967). Either of these figures suggests it is likely that nursing home employees will be interacting with hearing impaired individuals, making it important that nursing home employees have a knowledge of hearing loss, an understanding of its impact, and a repertoire of strategies for communicating with the hearing impaired population. It falls within the realm of the audiology profession to provide in-service programs that will supply this type of information to nursing home personnel.

Most comprehensive audiological rehabilitative programs within nursing homes include in-service training. Little research, however, has been done to determine what, if any, impact such training has had. Has such training, in fact, effected a change in attitude and opinion of these significant people who deal with older hearing impaired individuals? According to McCarthy (1987) bias and discrimination towards persons with hearing loss is 
pervasive and will only be overcome by providing information and education. The belief that hearing loss is a symptom of senility and mental inadequacy can be eliminated by providing information regarding the nature and effects of hearing loss. Informed care-givers will be better able to provide a reinforcing, positive environment and better care for people who are hearing impaired (McCarthy, 1987). An area to investigate relative to the impact of in-service training on nursing home personnel is attitude. By measuring the attitudes of people, it maybe possible to locate their position on a continuum from "very positive" to "very negative" (Mueller, 1940). By measuring attitudes before and after an in-service program, it might be determined if a change in attitude has occurred toward hearing impaired people. It is such a change which this study investigated.

\section{STATEMENT OF PURPOSE}

The purpose of this study was to determine whether an audiological in-service regarding hearing impairment in geriatrics and its effects on communication will result in increased positive attitudes toward older persons with hearing impairments. Specifically, this study proposed to formulate and present an in-service to nursing home personnel and then to measure the impact of the in- 
service through the use of attitudinal rating measures. This study sought to answer the following research question: will a comprehensive in-service which provides information about hearing loss, empathy training, and practical techniques for communicating with the hearing impaired geriatric effect a change in the attitudes of nursing home personnel toward geriatric persons with hearing impairment? 
CHAPTER II

\author{
REVIEW OF THE LITERATURE \\ HEARING LOSS IN THE AGING
}

Prevalence

Chermack (1981) noted that the effects of aging on the auditory system have been recorded in the literature since the late 1800 's when 2 waardenmaker published his article about the ranges of hearing at various ages. Corso (1977) stated that presbycusis (Ioss of hearing due to aging) is the most common auditory deficiency in adults. It ranks second only to arthritis in terms of being the most prevalent chronic condition which affects the health of the elderly (Harris, 1978).

It has been estimated by the us Bureau of Census in the 1986 statistical Abstract of the Us that there were 28 million people 65 years of age and older in 1984. As Chermack (1981) reported the us Health Interview Survey, 1976, showed that the prevalence of hearing loss increases from 28 at ages under 18 years to 308 at 65 years and older for noninstitutionalized persons.

In nursing homes or institutionalized settings, the estimation of hearing impairment is higher yet. Chaffee 
(1967) found 908 of nursing home residents had significant hearing impairment. Similarily, in their study of a nursing home sample, Schow and Nerbonne (1980) found 828 with significant hearing loss. In another study, Bloomer (1960) found a 518 prevalence rate. These prevalence studies thus suggest that from 508 to 908 of the residents of nursing could have hearing losses as compared to 308 of people over 65 in non-institutionalized populations. This makes hearing loss a major medical issue in nursing homes today.

Consequences of Hearing Loss

The consequences of hearing loss include three categories: (a) impact of the hearing loss on speech understanding, (b) the perceptions of others of the hearing impaired individual, and (c) the psychological issues that follow hearing loss.

Impact on Speech Understanding. Hearing loss affects a person's ability to discriminate consonants and the ability to understand speech in noise. Generally, nursing home personnel are dealing with a hearing loss that is the result of presbycusis. Presbycusis is characterized by a progressive, bilateral, symmetrical loss of hearing due to changes in the auditory system as a result of aging. The site of lesion is typically in the inner ear, and recruitment (low tolerance to loud sound) is often present 
(Chermack, 1981; Corso, 1984). It is, according to corso (1977)," the most common source of auditory deficiency in adults" (p.17l). Some of these hearing losses may have other etiologies such as noise damage, drug-induced hearing loss, vascular problems which alter the flow of the blood to the inner ear, tumors, and hereditary factors (Condit \& Ortenzo, 1985).

The frequencies involved and the severity of a presbycusic loss vary from one individual to another, although the commonality among the hearing losses is a dramatic impact on thresholds above $1000 \mathrm{~Hz}$. The reduced ability to hear at these higher frequencies often affects a person's ability to perceive high frequencies and decreases a person's ability to understand the speech of others in background noise.

Essentially, speech information is provided by acoustic energy produced at frequencies between $100 \mathrm{~Hz}$ and $8000 \mathrm{~Hz}$. As the ability to hear decreases between these frequencies, less information regarding vowels and consonants is available to the 1 istener. The identification of vowels is dependent on the first and second formants (peaks of energy); whereas, consonant identification is dependent upon the higher frequency components. In speech, vowels are more powerful, of longer duration, and carry less intelligibility information than 
consonants. Conversely, consonants have less power, are of shorter duration, and carry $60 \%$ of information needed for intelligibility (Chermack, 1981; Hull, 1982).

The acoustic characteristics of phonemes, when coupled with the sensorineural loss of an aging ear, create difficulties in understanding speech. With nearly normal hearing in the low frequencies, people are aware of the presence of sound because they are hearing the more powerful, longer-duration vowels. However, with decreased sensitivity to sound in frequencies above $1000 \mathrm{~Hz}$, they are more likely to miss or misunderstand speech. In these circumstances they are less likely to hear consonants, resulting in reduced intelligibility of speech (Chermack, 1981; Gerber, 1974; Hull, 1982). Thus, for example, a person with a high frequency loss may have difficulty distinguishing between. "fin" and "thin" or "fake", "cake" and "sake" (Newby, 1979).

This loss of hearing in the high frequencies also negatively affects the understanding of speech in ambient noise (Arnst, 1985; Hull, 1982; Maurer \& Rupp, 1979). Because geriatric persons generally have better hearing in the lower frequencies, there is an abnormal relationship between the lower and higher frequencies in speech. This means there is a disproportionate awareness of low frequency environmental noise and of the low frequency components of speech (Hull, 1982). This background noise 
not only masks low frequency speech information, but spreads upward to mask the already tentative high frequency phonemes (Chermack, 1981; Hull, 1982; Maurer \& Rupp, 1979).

The awareness that background noise creates more listening difficulties is important information for nursing home personnel. A study conducted by Moriarity (1976, in Maurer \& Rupp, 1979) showed that the average noise level inside 26 metropolitan nursing homes was 65 dBA. This would certainly stress a hearing impaired person's ability to communicate.

In summary, the configuration of hearing loss affects the ability to discriminate consonants, and to understand speech in noise.

Perceptions by Others. The second consequence of hearing loss goes beyond the objective threshold results described above. Nursing home personnel will find other secondary issues related to how the hearing impaired individual is perceived by others. Arnst (1983) suggests that frequently inappropriate responses of the older hearing impaired person create an image of "senility" which may in fact not be the case. According to Bloom, Duchon, and Frirer (1971), difficulty in conversation creates tension between the older adult and the family. This impatience of normal hearing people and frequent 
inadequate responses of the hearing impaired of ten create the impression that the older adult is senile. Too often the hearing impaired elderly are incorrectly labeled by their families and others as confused, disoriented, uncooperative, and noncommunicative. If amplification does not prove useful because of the complex nature of the presbycusis, the fear that the disorder is mental, rather than physical, is reinforced (Butler \& Lewis, 1977; Hull, 1982).

Psychological Factors. The third consequence of hearing loss is the psychological issues that may follow. Responses such as depression and isolation may need to be addressed in the nursing home (Chermack, 1981). Several authors have postulated which factors precipitate these emotional responses.

Ramsdell (1978) postulated that hearing fulfills three psychological functions: primitive, warning, and symbolic. The primitive level refers to the continual flow of background noise to which little attention is paid. For example, unless attended to, the ticking clock or refrigerator motor will go unnoticed. The warning level alerts one to dangers in the environment, such as a siren or car horn. The symbolic level enables the use of sounds as symbols for the purposes of communication. Depression, as hypothesized by Ramsdell (1978), is a consequence of loss at the primitive level. The 
individual is cut off from auditory contact with the environment, losing that "quiet hum" of life which reassures individuals that they are a part of the world.

McCall (1981) indicated that the depression from hearing loss is often enhanced by social factors. Some of these factors identified are:

1. fewer opportunities for conversation and the embarrassment of misunderstandings;

2. missing the message conveyed by a speaker's tone of voice;

3. the humiliation of being thought incompetent and stupid:

4. the impossibilities of easy participation in discussions, groups, meetings, committees, and lectures;

5. the depreciation of humor and verbal exchange;

6. the fatigue caused by constant alertness since the concentration needed to communicate is very demanding ;

7. the loss of social information from which to select, evaluate, and formulate opinions and assess the social mood; the inability to do two things at the same time (eat and lipread, for example);

9. the reasons for decisions not being clearly 
understood and being excluded from decisionmaking ("I'll tell you afterwards" is no use. 'Afterwards' is too late to participate);

10. the lack of stimulation through discussion and debate;

11. the uncertainty caused when people act unexpectedly without explanation;

12. the enormous difficulties of previously simple encounters, e.g., understanding the grocery clerk or waitress who will not write things down; and

13. the risk of paranoid feelings and the reality of being left out.

The enormity of the emotional impact that these factors can have on an individual's life is overwhelming. It is possible that any combination of these social factors could lead to depression.

Corso (1984) also stated that the major impact of presbycusis is on social communication. A hearing loss can undermine an individual's ability to pursue and maintain interpersonal relations leading to a sense of frustration and isolation. Withdrawal can be adopted as a coping mechanism when the stress of interaction becomes too great. This easily results in feelings of depression, insecurity, and a generalized suspiciousness. 
IN-SERVICE TRAINING

In-service training is an integral component of all creditable audiological rehabilitative programs. The caregivers must understand the goals and methods of a rehabilitative approach in order to support them. The staff must be supportive if the rehabilitation is to be successful (Alpiner, 1978; Kaplan, 1979; Schow \& Nerbonne, 1978).

According to Chermack (1981), it is the staff who creates the environment for residents. With education they are in a much better position to foster good communicative environments, encourage hearing aid use, detect possible auditory problems, and make referrals for treatment. As Hull (1982) notes, the staff provides carry-over into the daily life of the patient.

Attitude Change and In-service Training

This author's review of the literature revealed two relevant studies conducted in this area. They were a 1981 study by Dancer and Keiser on the effects of empathy training on geriatric-care nurses and a 1985 study by Dampier, Dancer, and Reiser on changing attitudes toward older persons with hearing loss. In both studies, the authors contended that previous in-service programs had 
focused too much on "academics". Their belief was that the purpose of an in-service is threefold: (a) it should lead to a better understanding of the impact of hearing loss on the communicative abilities of the person affected, (b) increase the learner's willingness to help older persons who have hearing impairments, and (c) provide specific suggestions that the learner can use to increase the likelihood of successful communication. They felt that academically-oriented in-service programs are less successful in achieving these three purposes than training related to the development of empathy toward hearing impaired older persons.

To ascertain the impact of in-service training, a semantic-differential scale using 25 polar adjectives was developed to measure attitude change. This scale was used in both studies (Dampier et al.1985; Dancer \& Keiser, 1981). Subjects responded to two statements with the 25 polar adjectives. The statements were: (a) "Hearing impaired elder persons are " and (b) "I feel toward hearing impaired elderly persons with hearing loss". The first statement was designed to measure perceptions and the second feelings.

In their 1981 study, Dancer and Keiser's subjects were 10 elder-care nurses. Using an audiotape intended to elicit empathy, they measured change in their subjects' 
perceptions/feelings toward hearing impaired geriatric persons with the semantic-differential 25 polar adjective scale which they developed. Their results showed no significant change in the nurses' perception of hearing impaired geriatric persons, but a significant change in their feelings toward hearing impaired geriatric persons. The lack of change in perception was hypothesized to be due to the fact the "the geriatric nurses have daily contact with older persons and probably have formed perceptions of older persons with hearing impairment based on every day exposure" (p.9).

This study was followed by the research of Dampier et al. (1985). To further test their hypothesis that academically-oriented in-service programs are less successful, they arranged for two training tapes. One was the same empathy-oriented tape used in the Dancer and Reiser (1981) study and the other was education-oriented. Before and after each tape, the subjects completed the same attitude assessment scale as in 1981. The researchers found significant change in attitudes after the empathy tape for both the perceptual and feeling statements. There was no significant change on the feeling statement after the lecture tape, however, there was a significant change in their perceptual ratings. Cumulatively, in the subjects' feelings and perceptions toward hearing impaired geriatrics, the empathy tape produced $40 z$ change and the 
lecture tape 188 in the subjects feelings and perceptions toward geriatrics who are hearing impaired.

This researcher believes that the above research makes a case for the inclusion of empathy training during an aural rehabilitative in-service program, but that it does not negate the importance of factual information. While in 1985, the lecture tape only elicited an $18 \%$ change in attitudes compared to $40 \%$ by the empathy tape, it did produce a significant percentage shift. Having listened to both the tapes, this researcher believes that it is possible that the difference in impact between the two tapes could be due to the presentation style. The lecture tape seemed "dry" and unenthusiastically presented while the empathy tape had more "life" and animation. 
CHAPTER III

\author{
METHODS
}

\title{
GENERAL PLAN
}

The intent of this study was to determine if an inservice program presented by this researcher on hearing loss and aging had an impact on how nursing home personnel perceive and feel about hearing impaired geriatrics. To measure change in the subjects' perceptions and feelings toward this population, they were asked to complete a 25 point bi-polar semantic-differential scale in response to two statements before and after the training. These two statements were: (a) "Hearing impaired elderly persons are " and (b) "I feel toward hearing impaired elderly persons." The in-service program integrated 3 areas of training. First, the subjects were given basic information about the ear and hearing loss. Secondly, the subjects were exposed to listening situations through a tape that replicated the experiences of hearing impaired geriatric persons, with the intention of inducing empathy. Lastly, they received practical information regarding communicating with hearing impaired 
people. Results from the first administration of the scale were then compared to determine if the postinservice ratings showed any attitudinal change.

\section{SUBJECTS}

Fifty-three nursing home personnel from one oregon and two Washington nursing homes served as subjects. All had at least 2 hours of direct patient contact per working day. An informed consent letter (Appendix A) was signed by each participant prior to participation in the study.

\section{INSTRUMENTATION}

The semantic-differential scale (Appendix B) used in this research was developed by Dancer and Keiser (1981). It was used to measure attitude change toward hearing impaired geriatrics by nursing home personnel before and after participation in the in-service. The scale consists of 20 bi-polar adjectives representing favorableunfavorable descriptors, e.g., grateful-ungrateful and kind-cruel. The adjective pair "serious-humorous" was eliminated prior to tabulating results, since neither could be considered having a negative or unfavorable connotation. As in previous research using this scale, five items were included for a validity measure in that responses to these should remain basically the same on both the pre and post-tests (e.g., cold-hot, blue-yellow). 
The scale was designed so that in response to a statement, subjects assigned a value along a 7-point scale for each pair of adjectives. The most negative rating between the adjective pairs was assigned a score of 1 and the most positive rating was a score of seven. The most negative rating score a subject could have was 19 and the most positive was 133. The two statements to which the subjects responded with the 25 bi-polar adjectives were:

1. "Hearing impaired elderly persons are

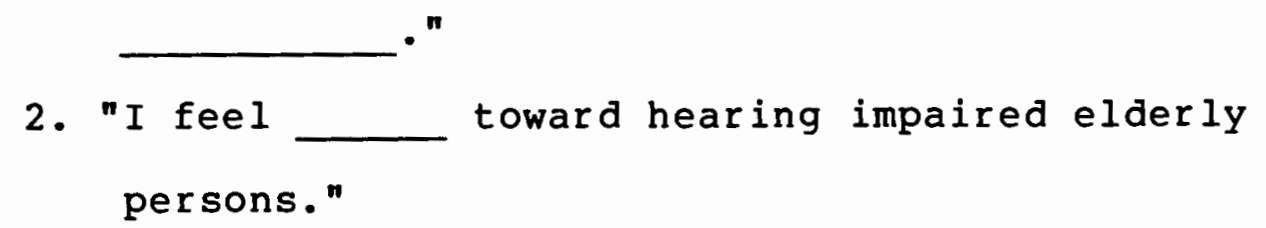

The first statement was intended to evaluate the subjects' perceptions of hearing impaired older people and the second, their feelings about impaired older people.

\section{PROCEDURES}

The attitude assessment scale was administered immediately prior to the in-service program. It was administered again immediately after the training. It was originally intended to administer the scale 30 days after the in-service to determine if the attitude changes continued. However, the facilities involved were uncooperative in returning these rating scale, so this information was not available. Each time the scale was 
given, the order of the adjectives was randomly rearranged. Subjects were given written instructions (Appendix C) which were read aloud by this researcher who then explained the continuum points using number $I$ as an example. This researcher then answered questions if any were asked by the subjects.

\section{$\underline{\text { In-service Training }}$}

The length of the in-service training, including the pre- and post-ratings, was approximately 1 hour. It was conducted by this researcher and three areas were then addressed. One component was an empathy training tape. The items on the tape were chosen from several sources, including an interview with a 98 year-old hearing impaired woman conducted by the researcher, a difficult listening test which simulated how words are heard through impaired ears, and a section which dramatized the sometimes negative responses of normal hearing people to the hearing impaired. Different portions of the tape were used throughout the training. A second component of the training was presentation of basic information about anatomy and physiology, hearing loss, and presbycusis. The third component was training in how to communicate with hearing impaired geriatric persons. A more detailed description is provided in Appendix $D$. 
CHAPTER IV

\section{RESULTS}

This study sought to answer the following research question: Will a comprehensive in-service which provides information about hearing loss, empathy training, and practical techniques for communicating with the hearing impaired geriatric affect a change in attitudes of nursing home personnel toward geriatric persons with hearing iwmpairment? In-services were given to 53 nursing home personnel and pre- and post-presentation ratings were made relative to attitudes toward geriatric persons who are hearing impaired. After eliminating incorrectly completed rating scales, there were 34 subjects for each statement. Subjects whose rating scores did not change were not included in the statistical analysis, leaving a total of 31 subjects.

Over 808 of the responses to the five neutral adjective pairs were initially within the neutral category (rating of 4 ) and remained so after the in-service presentation. As the ratings for these items remained neutral on both the pre- and post-rating scales, this is 
an indicator that the subjects were not randomly marking items.

The most negative score possible for each subject was a total of 19; 133 was the most positive score possible; and a completely neutral score would have been 76 . The mean for the feelings statement for the 34 usable subjects was 97.76 on the pre-test and 94.76 on the post-test. For the perception statement of 34 usable rating forms, the mean was 86.50 on the pre-test and 86.18 on the post-test. These scores indicate negligible average differences between the pre- and post-ratings. Further, they also show that the average attitude of each subject was on the positive side of neutral, both before and after the inservice. The raw scores for individual subjects also show a tendency of neutral and positive ratings on both the pre- and post-ratings (Appendix F).

The Wilcoxon Matched-Pairs Signed Ranks Test was used to determine if there was a significant difference in the attitude of each subjects' feelings and perceptions toward hearing impaired elderly persons on the pre- and postrating scales. Thirty-one subjects were used for analyzing each of the statements. Statistical analyses showed there was no statistically significant difference between the pre- and post-ratings for either the subjects' feelings ("I feel toward hearing impaired geriatrics") or perception ("Hearing impaired geriatrics 


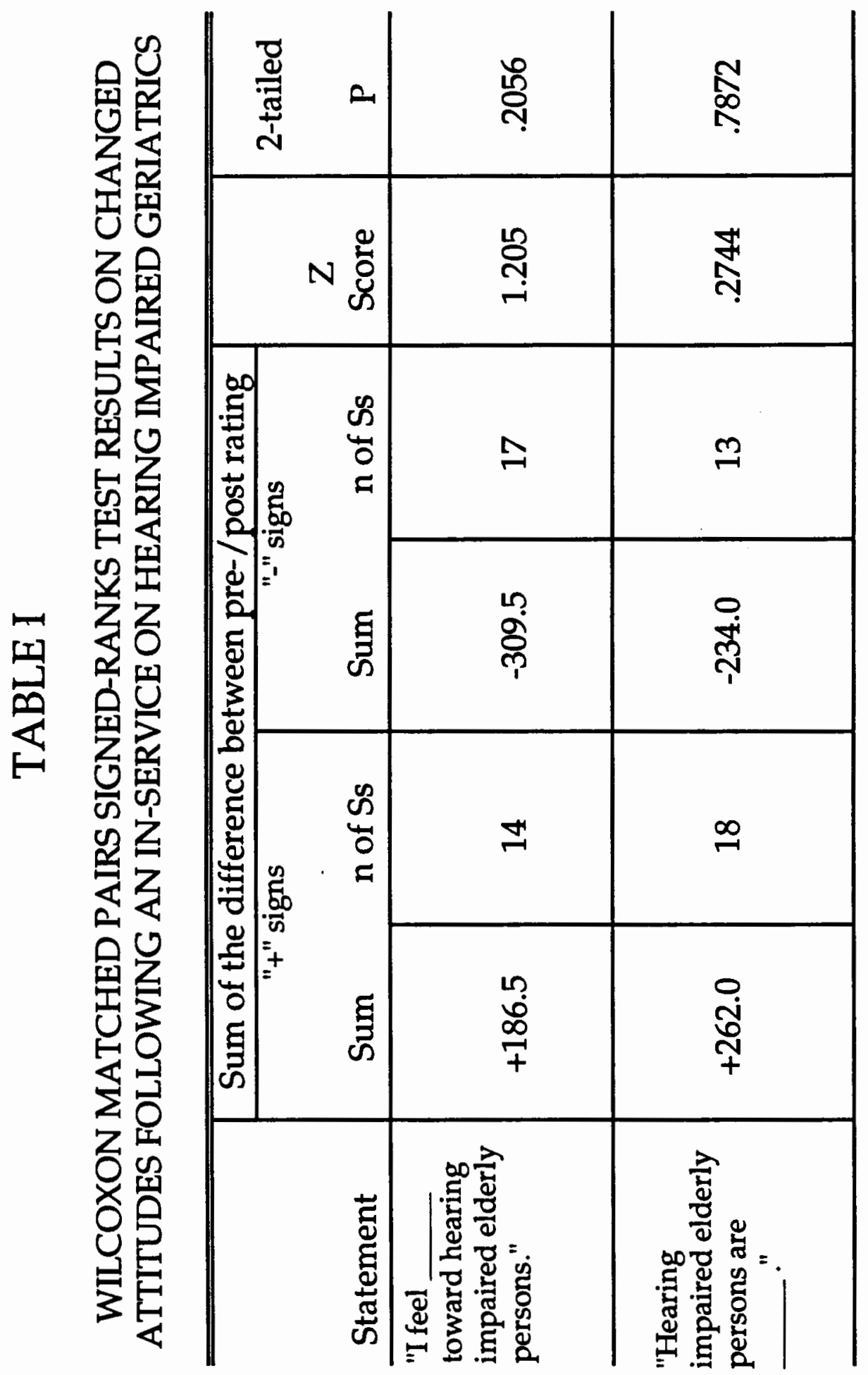


are ") regarding hearing impaired geriatrics. As Table I displays, the probability for the pre-/postrating difference was .2056 for the feelings statement and .7872 for the perception statement.

\section{DISCUSSION}

Several factors affecting the equivocal outcome of this study could be hypothesized. Attendance of the inservice at two of the three sites was voluntary, while it was mandatory at one site. The mandatory site provided the largest number of subjects (21 for the "I feel ....." and 23 for the "Hearing impaired ....." statement). This researcher's impression is that many in this group of subjects "resented" attending the in-service which was demonstrated through some potential subjects refusing to sign the human subjects form and asking questions relative to the reason for the in-service being held and the length of it. It was necessary to re-explain how to complete the pre- and post-ratings on an individual basis to some subjects because they stated they had not listened during the group explanation. After the in-service, one supervisor apologized for the group's attitude. As a result of this experience, when compared with the other sites, this researcher concludes that voluntary attendance is preferable.

Another factor apparent at all three sites was the 
impact of time. Supervisors expressed reluctance to give 1 hour to an in-service. In questioning staff about the preferred length, the concensus seemed to be 30 to 45 minutes. The in-service was lengthened by about 15 minutes by the pre- and post-ratings, possibly creating responses which were less than favorable. In other words, perhaps the ratings procedure itself contributed to negative results and no change in attitudes.

Another possibility is that a one-time in-service is a format which is not conducive to changing positively this particular population's attitude. Perhaps a series of short in-services on a variety of topics would have more impact. Additionally, it may be that the particular focus of this in-service may have been of little interest to these subjects. Topics such as hearing aids, troubleshooting hearing aid difficulties, or addressing a particular patient's hearing needs at their facility may have captured their attention. These topics, presented with the portions of the in-service intended to induce empathy, may have been more effective. It was apparent that participants were very attentive to the experiential portion. Listening to speech with high frequencies filtered and guessing what had been said appeared to capture their attention.

The subjects used in the two previous studies cited 
in the review of the literature (Dancer \& Keiser, 1981; Damper et al, 1985), using this same rating scale, were either registered nurses or college students. The majority of subjects in this study were certified nursing assistants. Particularly, Dampier et al. (1985) who used college students, found a definite positive change in attitude. The factor of educational levels may have played a role in the results of this research. Approximately 23 subjects in this thesis research were certified nursing assistants (CNA) and four were from housekeeping. It might be hypothesized that subjects in this study were less motivated than college students eager to cooperate or to learn more.

An additional variable in this study was the use of live voice presentation as opposed to a taped presentation.. This style was chosen because it was considered to be more stimulating. The comment could be made that a live presentation changes with each inservice. To avoid a change in the presented material, as much as possible, the same script was used by the researcher at each in-service. As this study was not comparing groups and was not looking at a change in each individual person, it was believed this variable would not affect the outcome.

In two respects, the instrumentation used for measuring the subjects' perceptions and feelings before 
and after the in-service may have also affected the outcome of this study. First, it is possible that this instrument was not sensitive enough in its measurement of change. If a subjects' attitude was already positive on the pre-rating scale, then the post-ratings may have not registered the more subtle change from positive to more positive, as it would have from a negative to positive change. Secondly, 19 out of the possible 53 subjects incorrectly completed the rating scale. It might be inferred from this that the scale was too complicated or confusing or cumbersome for some subjects. If the rating scale was perceived in this way, the very act of completing it may have resulted in negative feelings or hostility.

Lastly, some general negativity about participating in research and completing rating scales might be inferred from the lack of cooperation from all three sites in completing the 30-day post-ratings. Numerous phone calls and messages did not elicit even one completed form.

In conclusion, the format and/or content of the inservice presented to nursing home personnel subjects seemingly did not effect a change in attitudes towards hearing impaired elderly persons. Perhaps other inservice formats or a different instrument for measuring change would be more successful with this population. 


\section{CHAPTER V}

\section{SUMMARY AND IMPLICATIONS}

At least two studies have been found conducted in the area of audiological in-services and their impact on the people to whom they were presented. In 1981, Dancer and Keiser studied the effects of empathy training on geriatric-care nurses and in 1985, Dampier, Dancer and Keiser studied changing attitudes of college students toward older persons with hearing loss. Both of the studies investigated the effect of in-service training on empathy, rather than using the traditional academicallyoriented in-service program approach. Both studies found statistical results indicating a significant positive change in the subjects' feelings toward hearing impaired geriatrics. Additionally, Dancer et al. (1981) found a positive significant change in the subjects' perceptions of hearing impaired elderly persons.

This study investigated the effect of an in-service training program on nursing home personnel. The inservice that was developed included both empathy training and factual information. It was hypothesizd that both 
elements are important and the inclusion of both could result in a greater change in people's attitude. The empathy portion of this in-service included a taped interview with a hearing impaired older person, a tape dramatizing difficult interactions between hearing impaired and normal hearing individuals, tape of speech that simulated high frequency hearing loss, an "unfair listening test," and suggestions for interacting with hearing impaired people. The factual information included anatomy and physiology of the ear, types of hearing loss, common characteristics of hearing loss among older people, and the impact of hearing loss on speech understanding.

This in-service was given to the personnel at three nursing homes. Pre- and post-rating scales were completed using the same assessment scale as Dancer and Keiser (1981) and Dampier et al. (1985) had used. The subjects were asked to complete a 25 item bi-polar, semanticdifferential scale in response to two statements: (a) Hearing impaired elderly people are , and (b) I feel toward hearing impaired elderly people.

The Wilcoxon Matched-Pairs Signed Ranks test was used to determine if the rating scores on the pre- and posttests differed. Results showed no significant difference between the pre- and post-ratings for either the subjects' feelings about or perceptions of hearing impaired elderly people. 
Various possible factors affected the outcome of this study. Most sites and employees were reluctant to give one hour out of their workday, which was required to complete the study, possibly creating responses which were less than favorable on the pre- and post-ratings. The inservice without the pre- and post-ratings may have been more effective, although there is no way to measure this. The largest group of subjects were required to attend the in-service which appeared to create an atmosphere of resentment and non-cooperation. The results of this study led this researcher to recommend that attendance be voluntary for such in-services. The format and/or content of the in-service could be re-evaluated. Shorter inservices, over a period of time may be more effective. The factual information could take another direction such as, hearing aids or troubleshooting. Perhaps the entire in-service could be experiential, such as hands on work with hearing aids, listening tests, etc. since all three groups responded positively to activities which required participation.

\section{IMPLICATIONS}

\section{Clinical}

Several clinical implications regarding the delivery of audiological in-services to nursing home personnel 
became apparent during the conduction of this research. The length of an in-service should be limited to 30 to 45 minutes, avoiding possible stress incurred when employees are away from their jobs any longer. One might consider presenting in-service information in more than one session so that the desired information would be imparted over time in shorter sessions. Attendance on a voluntary basis is preferable, hopefully eliminating any resentment generated from mandatory attendance. A topical focus chosen by the nursing home staff would more likely maintain a higher interest level. Lastly, experiential/hands-on exercises would seem to maintain audience attention.

$\underline{\text { Research }}$

Suggested research to follow might be: (a) using this same design, except give the pre- and post-test at different times; (b) using this same design, compare the attitude change in a group of college students versus certified nursing assistants; (c) using this same design, measure its impact on family members; (d) give a series of in-services to determine if the effect on attitudes would be greater than that of a one-time in-service and use the research design in Dampier, et al (1985), except with nursing home personnel as subjects; (e) develop a different instrument to measure change in attitude and use 
it in conjunction with the in-service used in this study. 


\section{REFERENCES}

Alpiner, J. (1978). Rehabilitation of the geriatric client. In J. Alpiner (Ed.), Handbook of adult rehabilitative audiology. Baltimore: Williams and wilkins.

Arnst, D. (1985). Presbycusis, In J. Katz (Ed.), Handbook of clinical audiology. Baltimore: Williams and Wilkins.

Bloomer, H. (1960). Communication problems among aged county hospital patients. Geriatrics, 15, 291-295.

Bloom, M., Duchon, G., \& Frier, G. (1971). Interviewing the ill aged. Gerontologist, 11, 292-294.

Butler, R., Lewis, M. (1977). Aging and mental health. Saint Louis: The C. V. Mosby Co.

Chaffee, C. (1967). Rehabilitation needs of nursing home patients: A report of a survey. Rehab. Lit., 28, 377382 .

Chermack, G. (1981). Handbook of audiological rehabilitation. Springfield, IL: Charles C. Thomas.

Corso, J. (1977). Auditory perception and communication. In J. Birren \& W. Schaie (Eds.), Handbook of psychology of aging. New York: Van Nostrand and Reinhold.

Corso, J. (1984). Auditory processes and aging: significant problems in research. Experimental Aging Research, 10, 171-174.

Dampier, K., Dancer, J., \& Keiser H. (1984). Changing attitudes toward older persons with hearing loss: comparison of two audiotapes. American Annals of the Deaf, $130,267-271$.

Dancer, J., Keiser, J. (1981). The effect of empathy training on geriatric-care nurses. Shhh, 2, 3-4.

Gerber, S. (1974). The intelligibility of speech. In S. Gerber (Ed.): Introductory hearing science: physical and psychological concepts. Philadelphia: w.B. 
Harris, C. (1978). Fact book on aging: A profile of America's older population. Washington $\bar{D}$.C.: The National Council on Aging.

Hull, R. (1982). Rehabilitative audiology. New York: Grune \& Stratton.

Jacobs-Conduit, L. \& Ortenzo, M. (1985). Physical changes in aging. In L. Jacobs-Condit (Ed.): Gerontology And Communication Disorders. Rockville: American SpeechLanguage-Hearing Association.

Kaplan, H. (1979). Development, composition and problems with elderly aural rehabilitation groups. In $M$. Henoch (Ed.) : Aural rehabilitation for the elderly. New York: Grune \& Stratton.

Lysons K. (1984) Hearing impairment. Cambridge: Woodhead-Faulkner.

Maurer, J. \& Rupp, R. (1979). Hearing and aging: Tactics for intervention. New York: Grune \& Stratton.

McCall, R.F. (1981). The effects of sudden profound hearing loss in adults life, paper given to the British Society of Audiology, July 10, 1981 .

McCarthy, P. (1987). Rehabilitation of the hearing impaired geriatric client. In J. Alpiner \& P. McCarthy (Eds.): Rehabilitative Audiology: Children and Adults. Baltimore:Williams \& Wilkins.

Mueller, D. (1940). Measuring social attitudes. London: Teachers College press.

Newby, H. (1979). Audiology. Englewood Cliffs: PrenticeHall, Inc.

Ramsdell, D.A. (1978). The psychology of the hard of hearing and deafened adult. In $\mathrm{H}$. Davis and $\mathrm{J}$. Silverman (Eds.): Hearing and Deafness. New York: Hold, Rinehart \& Winston.

Schow, R. \& Nerbonne, M. (1980). Hearing levels among elderly nursing home residents. Journal of Speech and Hearing Disorders, XLV, 124-132.

Schow, R., Christensen, J. \& Nerbonne, M. (1978). Communication disorders of the aged: A guide for health professionals. Baltimore: University Park Press. 
U.S. Bureau of Census (1986). Statistical abstract of the United States (106th edition.) Washington D.C.: U.S. Government. 
APPENDIX A

INFORMED CONSENT 


\section{INFORMED CONSENT}

I, - hereby agree to serve as a subject in the research project investigation of an audiological in-service entitled Audiological In-Service Regarding Hearing Impairment and its Impact on Communication in the Geriatric population conducted by Marie Lassell under the supervision of Mary Gordon, M.s.

I understand that the study involves completion of a questionnaire just prior to participating in the inservice and that after the in-service I will be asked to complete a second questionnaire and one month later a third questionnaire. Further, I understand that the entire process, exclusive of the third questionnaire will take approximately $11 / 2$ hours. Completion of the third will take approximately 10 minutes.

I understand that possible risks to me associated with this study are time away from my job. and a commitment to be present for the entire in-service study.

It has been explained to me that the purpose of the study is to learn the effectiveness this in-service has in providing information regarding hearing loss and aging.

I may not receive direct benefit from participation in this study, but my participation may help to increase knowledge which may benefit other in the future.

Marie Lassell has offered to answer any questions I may have about the study and what is expected of me in the study. I have been assured that all information I give will be confidential and neither my name nor identity will be used for publication or public discussion purposes.

I understand that I am free to withdraw from participation in this study at anytime without jeopardizing my course grade or my relationship with portland state University.

I have read and understand the foregoing information and agree to participate in this study.

Date

Signature

If you experience problems that are the results of your participation in this study, please contact the chair of 
the Human Subjects Research Committee, or the Director of Grants and Contracts, 303 Cramer Hall, Portland state University, 725-3417. 


\section{APPENDIX B}

RATING SCALES 


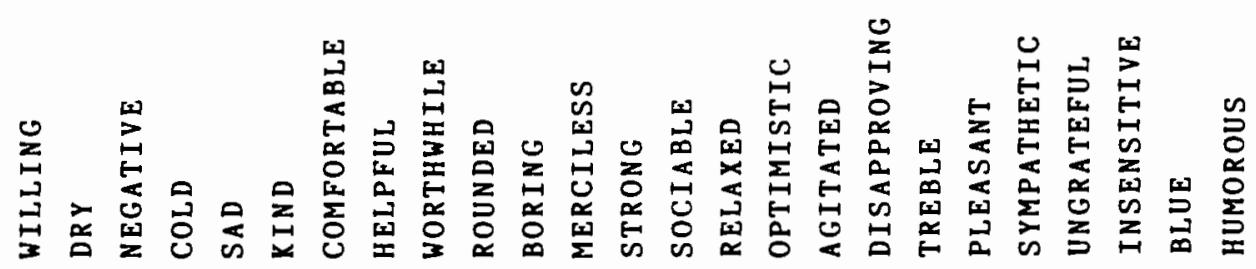
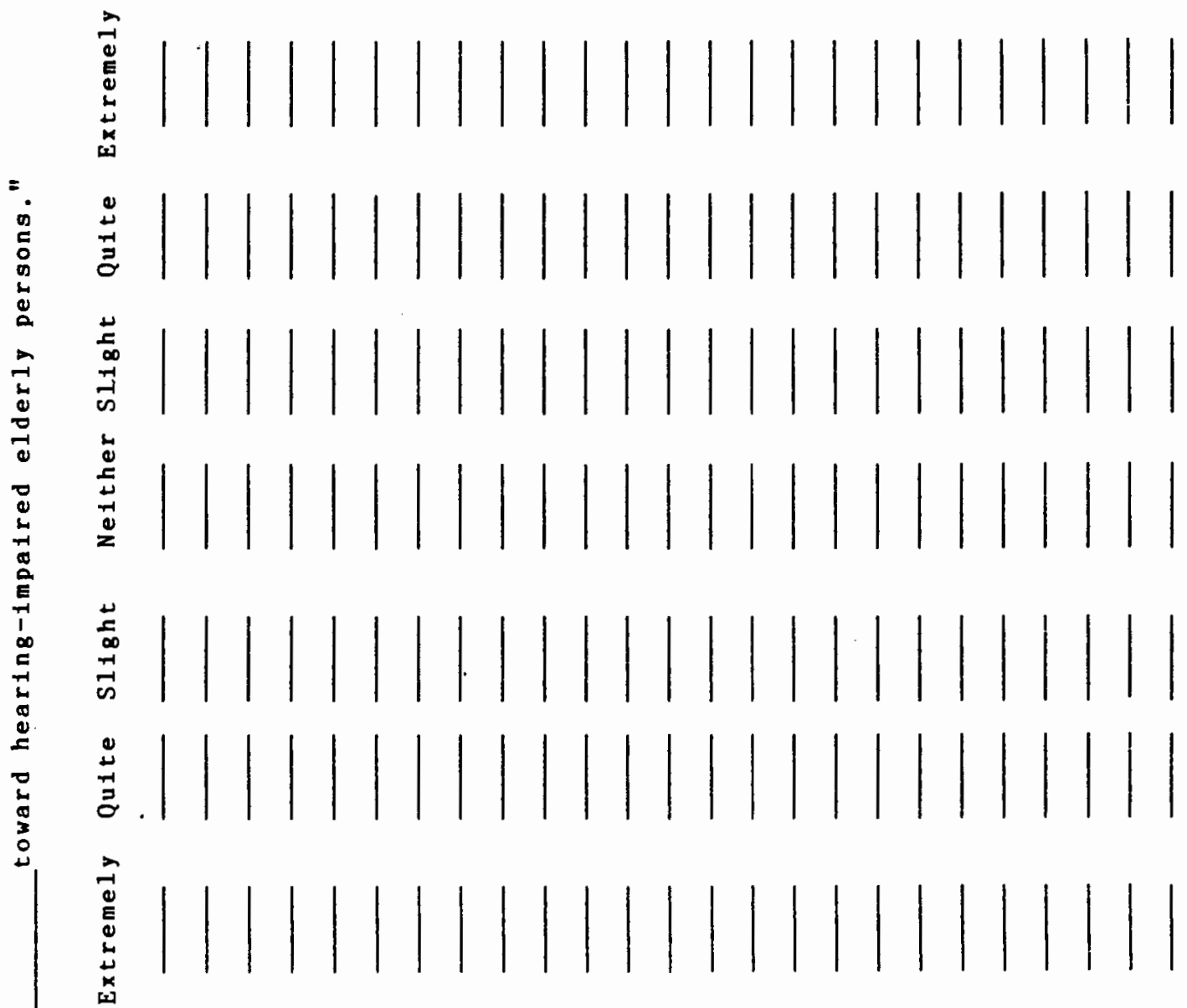

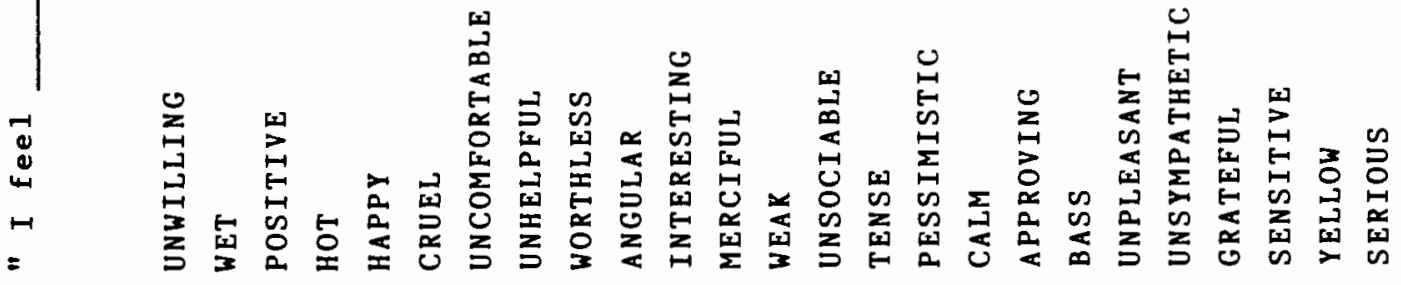




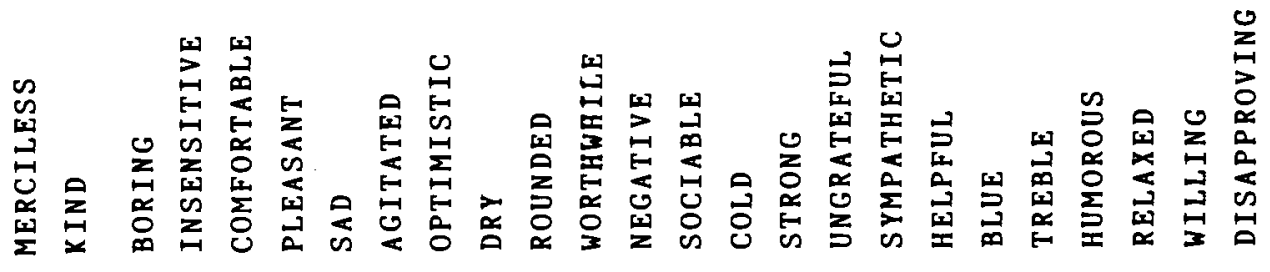

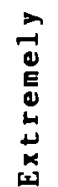

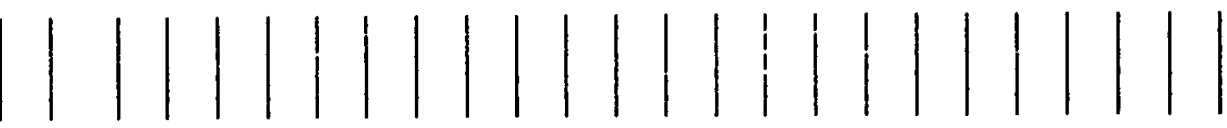

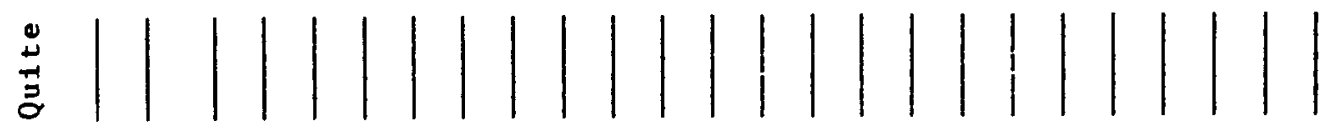

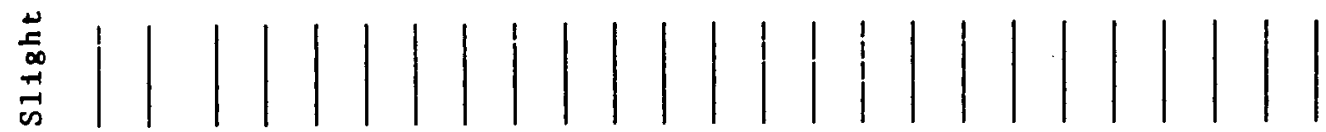

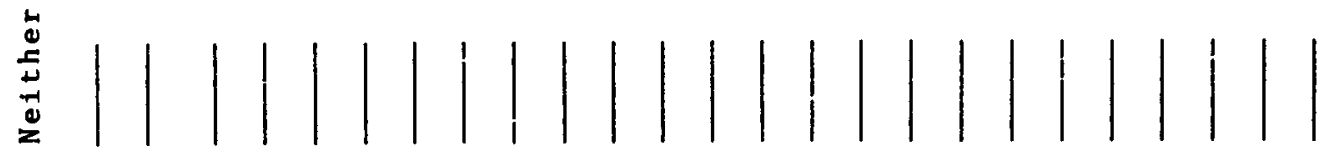

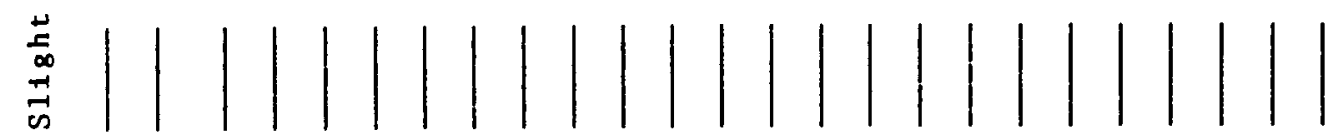

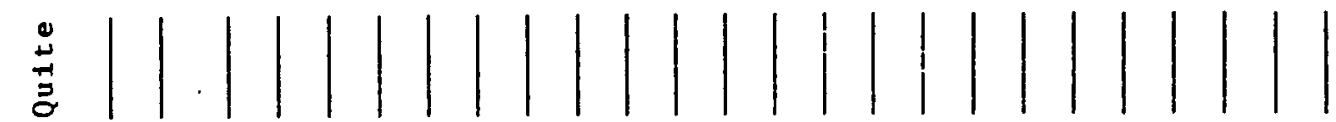

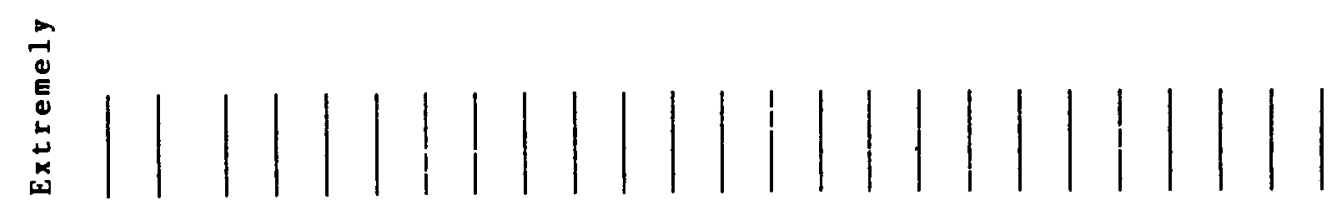

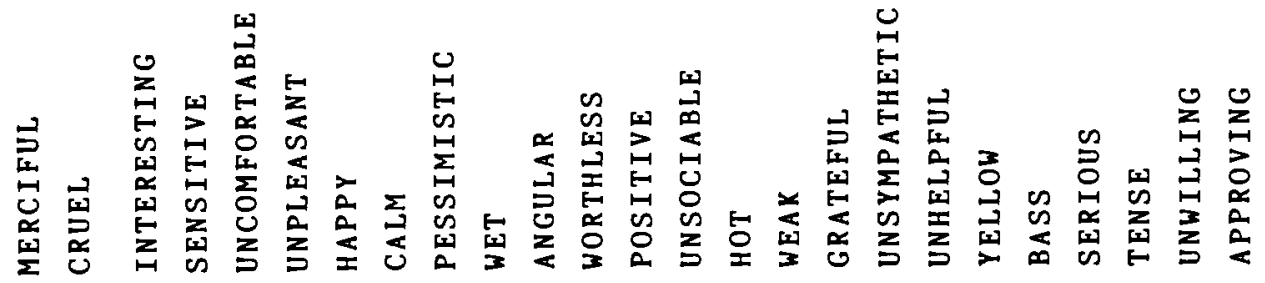


APPPENDIX C

INSTRUCTIONS FOR COMPLETING THE SCALE 


\section{Instructions for completing the scale}

You will find on the page in front of you a statement followed by pairs of adjectives, one on the left side of the paper and one on the right. Please choose a response to the statement for each adjective pair.

For example, if you $x$ 'neither' that indicates a neutral response to both adjectives. If you $x$ 'extremely' that indicates a very strong rating for the adjective to which it is closest, 'quite' is a little less strong response and 'slight' a smaller rating yet. Make one mark per adjective pair. It may be helpful to use the straight-line edge to guide you down the page. Please note there is a front and a back. If you have any questions, feel free to ask. 
APPENDIX D

OUTLINE OF IN-SERVICE SCRIPT PRESENTED TO NURSING HOME PERSONNEL REGARDING HEARING LOSS AND THE ELDERLY 
OUTLINE OF IN-SERVICE SCRIPT PRESENTED TO NURSING HOME PERSONNEL REGARDING HEARING LOSS AND THE ELDERLY

Tape -Interview with Bethel (98 year old woman)

I Anatomy and physiology of the ear

A. Basic Acoustics

When any type of sound is produced such as by speaking knocking on a table or a door bell, what is sent out from the source of the sound is a vibration or disturbance in the air. These vibrations are called sound waves. What our hearing mechanism does is pick up these vibrations and sends them up to the brain for translation.

First, what I am going to describe for you are the different sections of our hearing mechanism and the transformation or change that occurs to the vibration as it goes through the different hearing sections. I'll do this by giving a very basic explanation of the anatomy and physiology of the ear.

(Handout - anatomy of the ear)

B. Anatomy - There are three sections to the ear Looking at your handout, you will see they are the outer, middle and inner ear.

1. Outer ear

a. consists of the pinna/flap, the ear canal and ends at the eardrum.

b. Purpose - to collect sound vibrations and direct them to the eardrum.

2. Middle ear

a. This is an air filled cavity which contains the three smallest bones of the body: malleus incus, and the stapes. Each is smaller than a grain of rice.

b. You can see on the handout that the malleous, the first bone, is attached to the eardrum. Thus when sound vibrates the eardrum, it also vibrates the malleous, which in turn vibrates the other two bones, as all three are attached. The last bone, the stapes is set in a small entrance to the inner ear.

c. The purpose of the middle ear is to convert sound vibrations to mechnical energy. It moves the vibrations closer to the inner ear.

3. Inner ear - This, as you can see, is divided into 2 portions. The semicircular canals, which are for balance and the cochlea, which is for hearing. We are dealing only with the hearing portion. 
a. The inner ear is a fluid filled, snail shaped organ. Inside the cochlea are thousands of tiny hair cells which are set in motion whenever the fluid is disturbed. When hair cells are stimulated an electrical impulse is sent to the brain. It is the movement of the stapes in the oval window (entrance to the inner ear) that starts a wave motion of the inner ear fluid.

b. The purpose of the cochlea then, is to send the electrical message to the brain.

So, the sound vibration is collected by the outer ear, sent on through the middle ear via

the three bones, to the cochlea where the hair cells are disturbed and electrical message is sent to the brain.

II Types of hearing loss - There are two type of hearing loss, conductive and sensorineural.

A. Conductive- occurs in the outer and middle ear 1. Possible causes of hearing loss in the outer ear are impacted wax and collapsed ear canal.

2. Causes of hearing loss in the middle ear are fluid, otosclorosis (when normally hard bone is changed to spongy bone). It is important to remember that this space is normally air filled so anything that stops the bones from moving efficiently will create a hearing loss. Conductive losses can of ten be helped medically with antibiotics and surgery.

B. Sensorineural hearing loss occurs in the cochlea and pathways to the brain.

Hearing loss as we get older usually occurs in the inner ear. Here there is usually some disturbance or damage to the hair cells. When hair cells are destroyed some of the electrical messages will not get sent. A sensorineural loss can not be helped medically, but hearing aids are of ten very useful. So we have conductive loss occurring at the outer and middle ear and sensorineural occurring at the inner ear and nerve pathways.

\section{Presbycusis}

This is a two-bit word that we use to describe hearing loss due to aging. All this means is a decrease in hearing sensitivity that accompanies the normal course of living.

A. Statistics

There are approximately $20 \mathrm{million}$ people 65 years 41 of age and older. Of these 808 have a 
hearing loss and $1 / 2$ of these have hearing problems that actually interfere with communication ability and lifestyle goals. B. There are common characteristics among older people with hearing loss.

1. Gradual loss over years so... a person is often unaware that hearing has diminished. They don't realize they're no longer hearing the sound of leaves crunching, clocks ticking, sound of breathing or the bacon sizzling.

2. There is often an equal loss in both ears, usually sensorineural and usually affects high frequencies/pitches.

3. You will often hear the complaint "I can hear, but I don't understand."

4. Denial that a hearing loss exists is very prevalent by both the person with the hearing impairment and their friends. The reasons for denial can vary - fear of aging, vanity, fear

of failure, of trying something new.

TAPE - The following are dramatization of the negative impact denial can have on everyone involved.

C. Cause

The cause of presbycusis is difficult to determine. Living exposes our ears to many situations which have a negative impact on our hearing .

1. Noise is chronic offender, we live in a noisy society, encountering noise through our work, hobbies, cars, etc.

2. Some drugs can affect our hearing. Large amounts of aspirin can cause a drop in hearing and a group of drugs called aminoglicocides.

3. Just plain aging of the hearing mechanism. It doesn't function as well as it used to.

Degeneration of the neural pathways to the brain can affect our hearing ability.

These are some common causes of hearing loss in the elderly.

What will be addressed next is an explanation of the objective test results. I will tell you how hearing testing is done, what the information we gather means medically and the impact it has on the person's communication ability.

D. Hearing testing 
1. When an audiologist tests your hearing they put head phones over your ears and ask that you indicate when you hear a tone through the headset. He/she asks that you let them know even if the tone is very soft, some ask you to guess.

So they're looking for the very softest sound you can hear.

Handout \#2 - audiogram

2. They record the results on an audiogram similar to the one in front of you. -across the bottom are pitches or frequencies, low to high

-down side are loudness levels from a very soft sound at the top to a very loud sound at the bottom.

-Using an $x$ for the left ear and a circle for the right ear, the audiologist marks on the graph where the patient hears a tone about 508 of the time at each pitch.

Handout \#3 -Familiar Sounds

3. On this audiogram I have indicated where some familiar sounds fall: whisper, average speaking voice, rock band, phone. Notice where they

fall in terms of pitch and loudness.

Handout \#4 -Degrees of Hearing loss

4. This chart shows you at what point we consider

a person's hearing loss within normal limits,

a mild, moderate or severe hearing loss.

Handout \#5 Normal thresholds vs. High Frequency Loss

5. On this audiogram, I have shown you a person with a normal right ear, these are the filled in circles. Anything between 0 and 25 is considered normal hearing. You can see that the black filled circles are all between 0 and 25. The other

circles (gray dots) represent a person with a high frequency hearing loss. You can see that at the first two frequencies they are between zero and twenty five, however, the thresholds at the other pitches start falling outside of this range as the pitch gets higher.

Handout \#6 - Consonants and vowels

6. We tend to think of words as

single sounds, but every word is made up of a number of different sounds, some high and some low. Example $M$ a $r$ i The low frequency speech sounds tend to be vowels and the $h i g h$ frequency sounds are generally consonants. on the audiogram I've indicated where some 
speech sounds fall, on the average, in terms of loudness and frequency. Another very important difference between vowels and consonants is consonants carry the meaning in english, where vowels give us information about duration, stress, rhythm. Unless you catch the first consonant you may have trouble hearing the difference between thin, sin, fin, shin, and chin.

Handout \#7 - Vowels, Consonants and Normal vs. High Frequency Loss.

7. This graph takes the normal and high frequency loss and adds the information about where the vowels and consonants fall. Notice where this person's hearing loss falls and how he or she will be missing consonants. Remember it is the consonants that carry the meaning, the 'th' in thin and the 's' in sin are going to be lost.

Tape - We are now going to listen to some examples of filtered speech, where the high frequencies have been gradually eliminated. I want you to have an idea of what a hearing impaired person is listening to during normal conversational speech.

Tape - Unfair Listening Test. Now we are going to do what is called an 'unfair listening test'. I want you to

listen to each word and write down what you think you hear. These same words will presented a second time. During the second presentation you will receive more high frequency information. This is kind of fun and just give you an idea of some of the frustrations of living with a hearing loss.

$\begin{array}{lr}\text { 1. fill } & 6 . \text { wedge } \\ \text { 2. catch } & 7 . \text { fish } \\ \text { 3. thumb } & 8 . \text { shows } \\ \text { 4. heap } & 9 . \text { bed } \\ \text { 5. heap } & 10 . \text { juice }\end{array}$

IV Communication Techniques

All right, so now we know what it is like to have a hearing loss. So what can we do to help someone who is hearing impaired, what exactly is helpful. I have some suggestions.

Handout \#8 - Helping the Hearing Impaired older Person A. Visual information is very important to people with hearing loss. With this in mind think about 1. How close or far away are you from him or her. 3-9 feet is ideal. Get in close enough so they can see your facial expressions, watch lip movement.

2. How is, the lighting. Lighting from behind 
creates shadows on the face. Try to light up your face. Take off hats that might shadow your face.

3. Keep hands away from face.

B. Inability to hear in background noise is a major complaint of people with hearing loss so:

1. Turn down the TV or radio before you attempt to communicate.

2. Move to a quieter corner of the room.

3. There are also visual distractions, doorways, windows, etc.

C. Speak a little slower and a little louder.

Shouting tends to distort the sound. Speaking too slow distort lipmovement, so the information becomes useless to the listener.

D. Pause along the way. Allow the person time to absorb the information.

E. Let the person know you are about to communicate with them by beginning with their name or a touch on the shoulder. Anything that let's them know you want to carry on a conversation with them.

F. When asked to repeat, use different words, paraphrase, say it again with different words.

G. Warn the person of a shift in conversation. If you have switched from talking about the garden club to Sarah's first grade teacher, give an introductory statement indicating that.

H. Get their hearing aid out of the drawer. Encourage them to wear it. Check the battery. Let them know how much easier it is for you to communicate with them, if they wear their hearing

VI Closing aid.

My closing though is that you can have a great impact on a hearing impaired person's life. Letting them know you are willing to adapt, encouraging them to be assertive and to ask for what they need is the most empowering gift you can give them. You can assist them in enriching their lives and taking back control of what happens to them. 
APPENDIX E

HANDOUTS FOR IN-SERVICE 


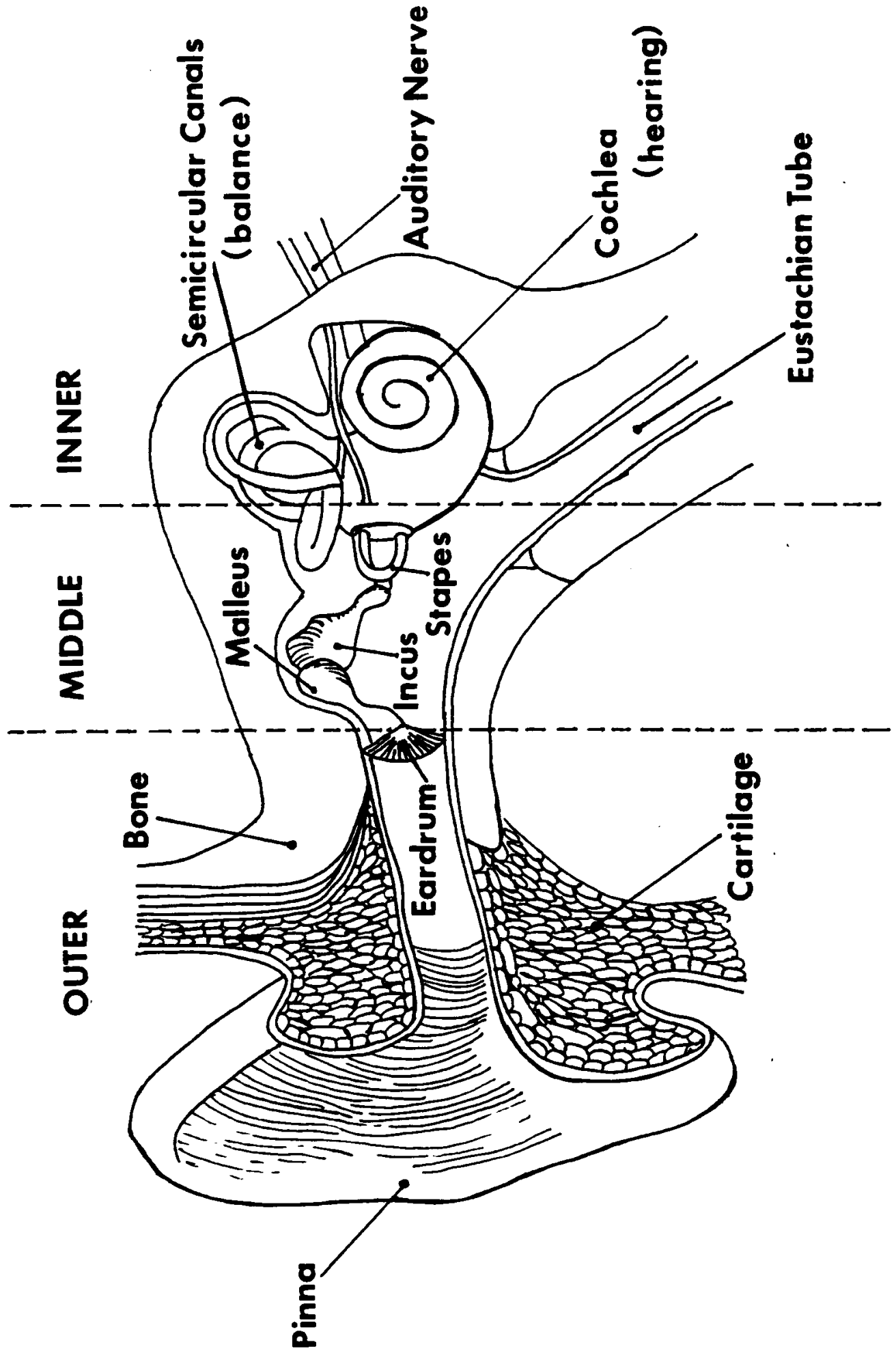




\section{Audiogram}

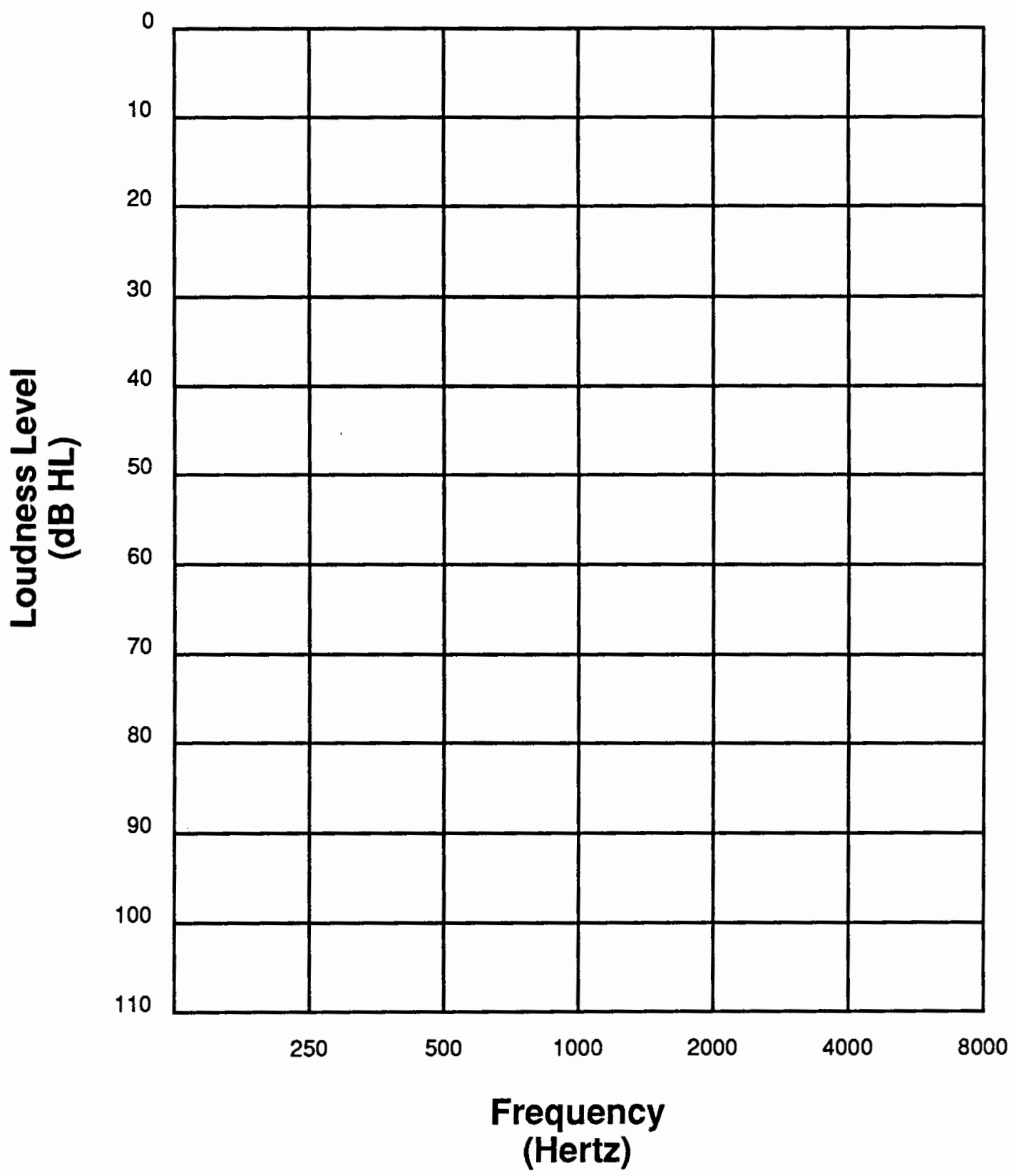




\section{Familiar Sounds}

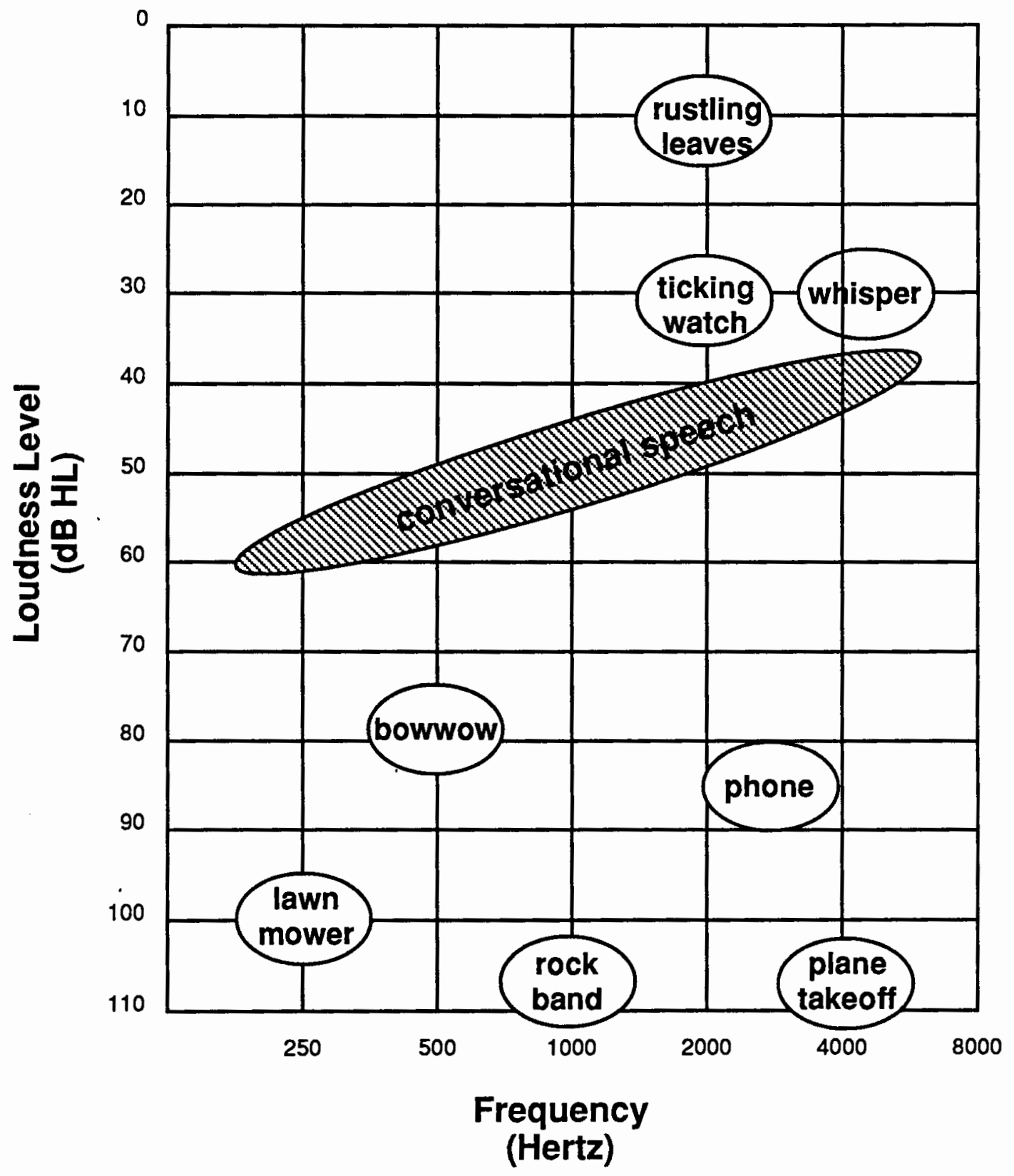




\section{Degrees of Hearing Loss}

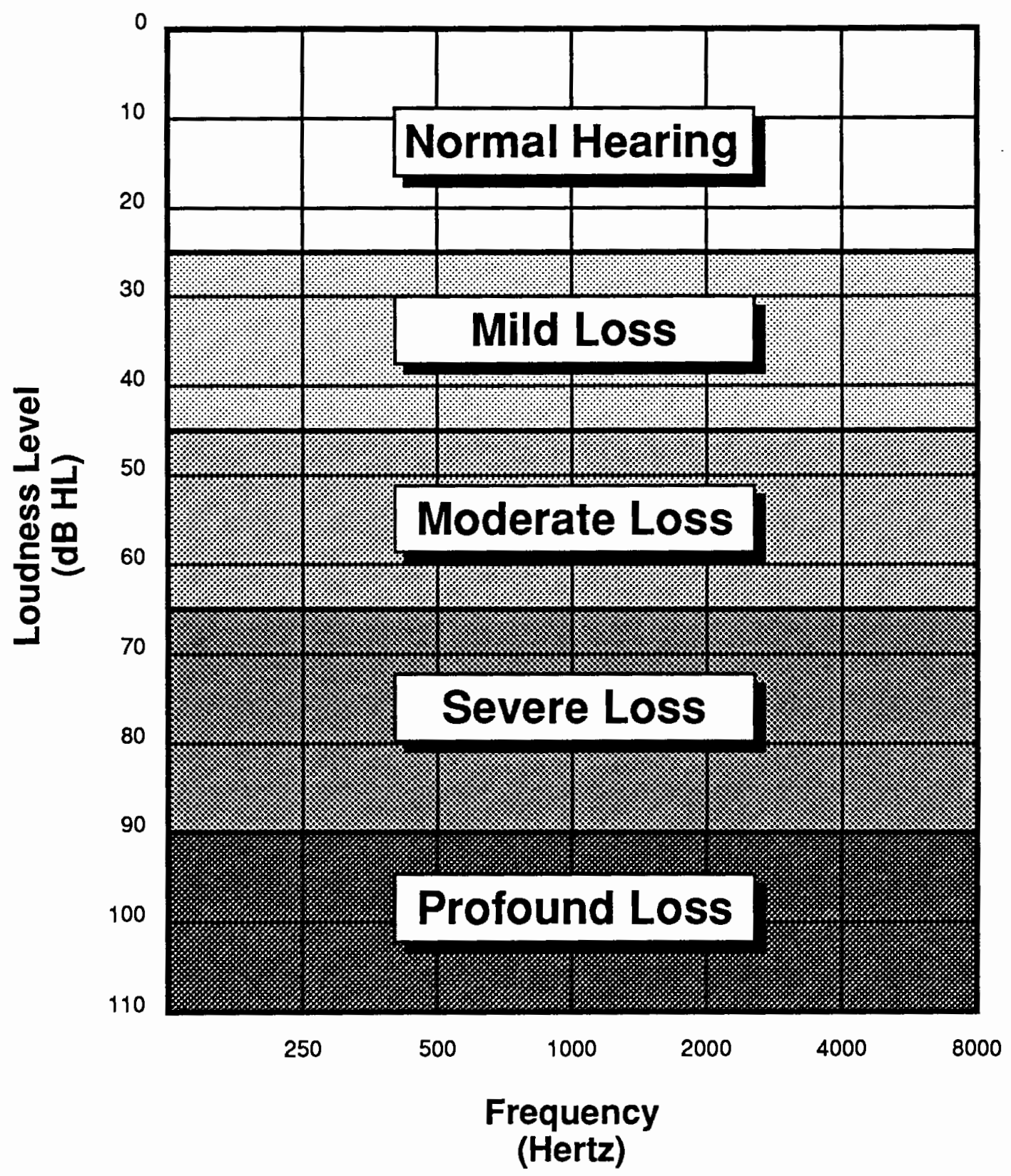




\section{Speech Sounds}

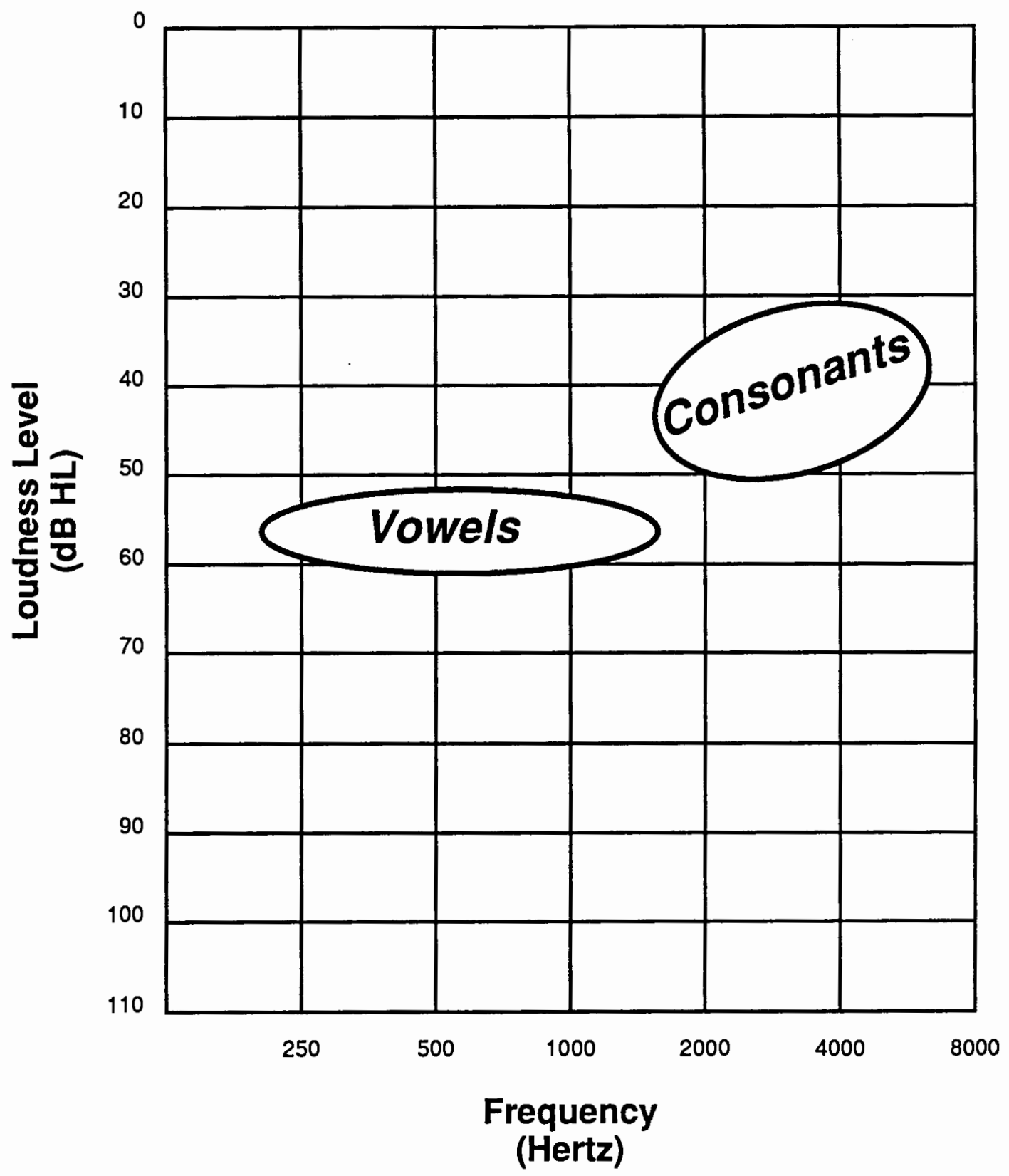




\section{Comparison of Normal and High-frequency-loss Hearing}
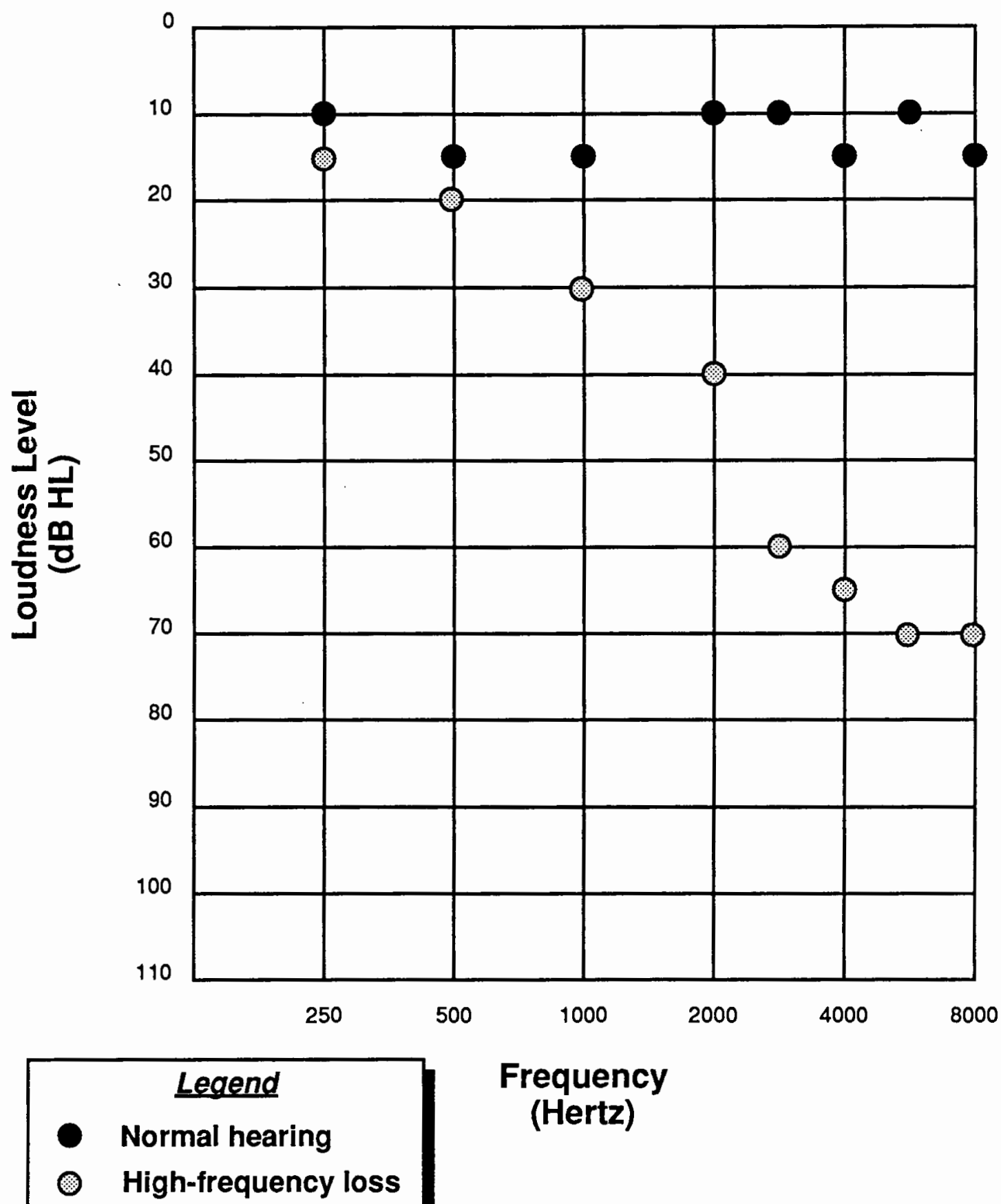

Frequency

(Hertz) 


\section{Comparison of Normal and High-frequency-loss Hearing}

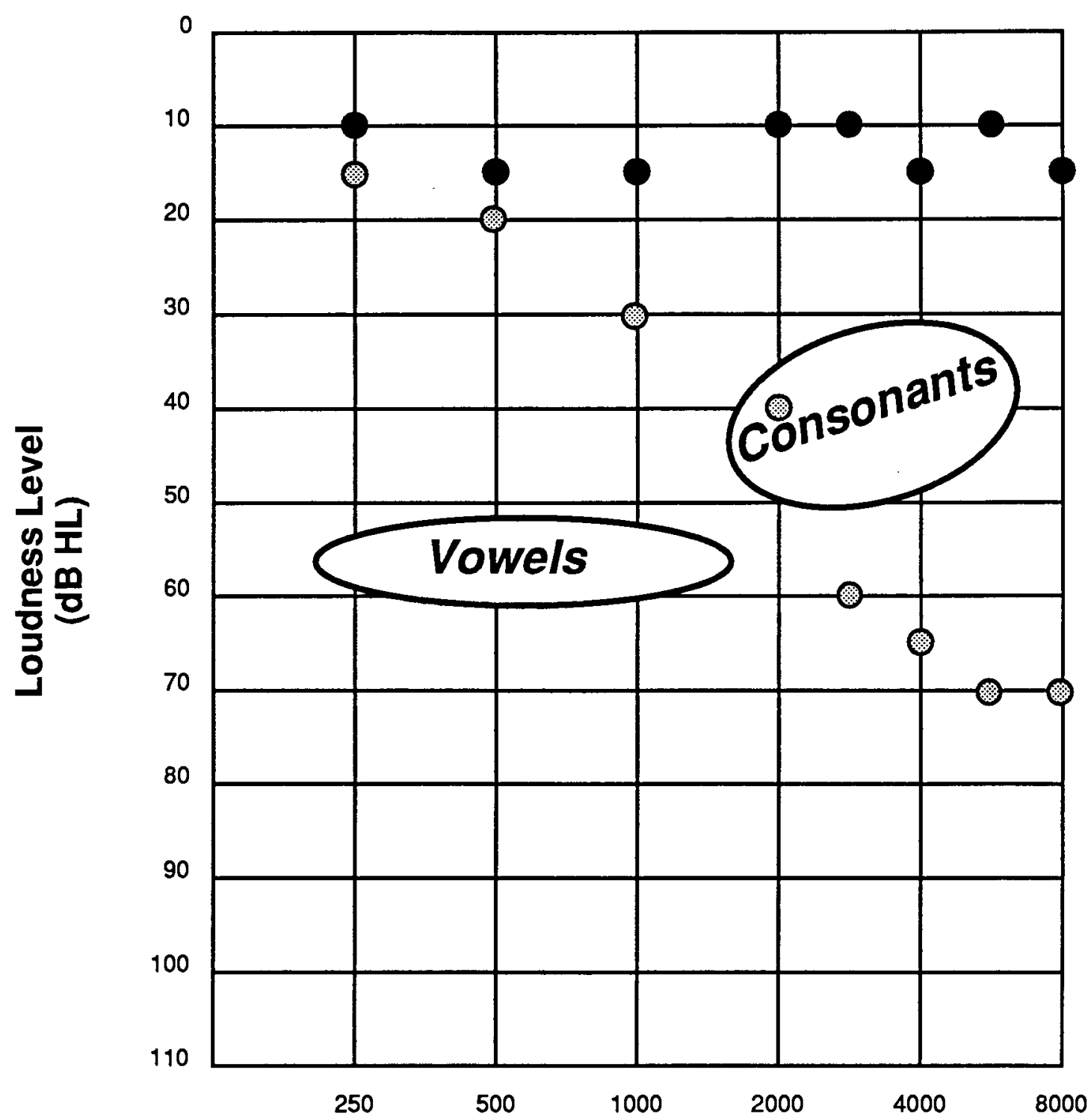
Legend
- Normal hearing
; High-frequency loss

Frequency

(Hertz) 
1. Move in close so that all the visual information available from facial expressions and lip movement can be seen by them. Three to nine feet is the ideal speechreading distance.

2. Check the light source. Again, an illuminated face makes visual information easier to use.

3. Keep hands away from face, gum out of mouth anything which obscures facial movements.

4. Before conversing with the older person, turn down any competing noise source (radio, television, busy hallways etc.) or ask the individual to move to a quieter spot. Background noise greatly reduces a person's ability to understand speech.

5. Speak slightly slower and slightly louder. Emphasis should be on slightly. If we speak too slow, lip movement is distorted rendering lipreading information useless. Speaking too loud distorts speech sounds.

6. Pause in your conversation to let your message sinkin.

7. Let the older person know you are going to communicate with them. Get their attention by beginning with their name or a gentle touch on the shoulder. Allow them to have a chance to put themselves in a listening mode.

8. It is very important that when you are asked to repeat, that rather than repeating the exact same words, you paraphrase the message. Say it again, but in different words.

9. Tell the older person when the topic of conversation has changed. ("Now, I want to tell you about Aunt Minnie's poodle").

10. Encourage the use of a hearing aid if they have one. Get it out of the drawer, check the battery for them. Reinforce that it is much easier for you to communicate with them when they are wearing their hearing aid. 


\section{APPENDIX F}

STATISTICAL DATA FROM PRE- AND POST-RATINGS FOR EACH SUBJECT 
APPENDIX F

STATISTICAL DATA FROM PRE- AND POST-RATINGS FOR EACH SUBJECT

"I feel toward hearing impaired elderly people." SUBJECT POST-TEST PRE-TEST DIFFERENCE

A

B

C

$\mathrm{D}$

E

F

G

$\mathrm{H}$

I

J

K

L

M

N

0

P

Q

R

S

T

U
107

101

76

106

86

88

89

90

83

95

114

113

83

85

97

75

81

102

71

76

101
102

98

95

104

105

94

92

104

96

77

112

110

80

91

107

77

77

118

72

76

87
$-16$

5

3

$-19$

2

$-19$

$-6$

$-3$

$-14$

$-13$

18

2

3

3

$-6$

$-10$

$-2$

4

$-1$

0

14 


$\begin{array}{lllc}\text { V } & 76 & 76 & 0 \\ \text { W } & 90 & 100 & -10 \\ \mathrm{X} & 124 & 128 & -4 \\ \mathrm{Y} & 66 & 65 & 1 \\ \mathrm{Z} & 127 & 143 & -16 \\ \mathrm{AA} & 103 & 100 & 3 \\ \mathrm{BB} & 84 & 97 & -13 \\ \mathrm{CC} & 105 & 106 & -1 \\ \text { DD } & 101 & 78 & 23 \\ \text { EE } & 133 & 133 & 0 \\ \text { FF } & 101 & 99 & 2 \\ \text { GG } & 91 & 133 & -42 \\ \text { HH } & 102 & 92 & 10\end{array}$

"Hearing Impaired elderly people are SUBJECT POST-TEST PRE-TEST DIFFERENCE

$\begin{array}{lllr}\text { A } & 99 & 95 & 4 \\ \text { B } & 78 & 76 & 2 \\ \text { C } & 81 & 78 & 3 \\ \text { D } & 103 & 105 & -2 \\ \text { E } & 90 & 95 & -5 \\ \text { F } & 75 & 75 & 0 \\ \text { G } & 94 & 92 & 2 \\ \text { H } & 75 & 75 & 0 \\ \text { I } & 83 & 90 & -7 \\ \text { J } & 95 & 91 & 4\end{array}$


K

L

M

N

0

P

Q

R

S

T

U

v

W

$\mathrm{x}$

Y

z

$A \dot{A}$

BB

CC

DD

EE

FF

GG

$\mathrm{HH}$
69

102

72

74

93

77

58

95

71

76

79

76

98

81

85

123

95

74

83

110

89

77

86

87
61

83

106

77

78

82

72

73

69

76

106

66

89

77

108

129

88

85

82

78

104

80

119

81
32

8

19

$-34$

$-3$

15

$-5$

$-13$

22

2

0

$-27$

10

9

4

$-23$

$-6$

7

$-11$

1

$-15$

$-3$

$-33$

6 